\title{
91 - Estudo da ação citotóxica de drogas antineoplásicas associadas ou não à dexametasona sobre as células de mastocitoma murino (linhagem p-815)
}

1- Pós-graduação do Departamento de Farmacologia do Instituto de Ciencias Biomédicas da Universidade de São Paulo, São Paulo-SP; Hospital Veterinário da Universidade Anhembi-Morumbi, São Paulo-SP 2-Professor Associado do Departamento de Farmacologia do Instituto de Ciências Biomédicas da Universidade de São Paulo, São Paulo-SP

O mastocitoma é uma neoplasia que acomete várias espécies animais, principalmente cães em medicina veterinária. Estes tumores refletem um mau prognóstico para os cães e o tratamento antitumoral instituído na maioria das vezes tem-se mostrado ineficaz. Este trabalho tem como objetivo estudar a ação citotóxica de quimioterápicos antineoplásicos como a vincristina, ciclofosfamida, doxorrubicina, paclitaxel e metotrexate associados ou nào ao glicocorticóide dexametasona sobre células de mastocitoma cutâneo murino in vitro, com a finalidade de contribuir com novos protocolos para o tratamento deste tumor. $\mathrm{A}$ utilizaçào de células de mastocitoma murino é justificada pela ausência de linhagem imortalizada de células caninas e pela grande variabilidade dos mastocitomas caninos (graus I, II e III), o que impediria a aquisiçào de conhecimentos básicos sobre o comportamento deste tumor in vitro. As células da linhagem P-815 de mastocitoma murino, adquiridas do Banco de Células do Rio de Janeiro, foram cultivadas em meio de cultivo RPMI, em estufa à $37^{\circ} \mathrm{C}$ e $5 \%$ de $\mathrm{CO}_{2}$, Em placa para cultivo de 24 poços, as células, previamente contadas em câmara de Neubauer, foram submetidas à ação das drogas isoladamente e associadas à dexametasona por $24 \mathrm{e} 12$ horas; e analisadas pelos métodos de exclusão do azul de trypan e citometria de fluxo, respectivamente. Pela análise estatistica de Kruskal Wallis, com comparações múltiplas, observou-se que as drogas vincristina, doxorrubicina e paclitaxel associadas ou não à dexametasona aumentaram a mortalidade das células P-815 e bloquearam o ciclo celular em G0/G1. A dexametasona, ciclofosfamida e metotrexate nào foram citotóxicas para as células P-815. Evidências descritas na literatura demonstram que a linhagem P-815 de mastocitoma murino tem comportamento semelhante ao mastocitoma cutâneo canino; assim, através de nossos resultados, podemos concluir que os quimioterápicos mais indicados para o tratamento dos mastocitomas seriam a vincristina, justificando o seu atual emprego clínico, a doxorrubicina, ainda pouco explorada, e o paclitaxel, não descrito em literatura para 0 tratamento deste tumor.

\section{2 - Linfoma multicêntrico com metástase no sistema nervoso central em cão. Relato de caso}

Aptekmann, K.P.'; Okamoto, C. E. ${ }^{2}$; Moutinho, F.Q. ${ }^{3}$; Campos, K.C.H. ${ }^{4}$; Takahira, R.K. ${ }^{3}$
1 - Residente em Clínica Médica de Pequenos Animais da Faculdade de Medicina Veterinária da Universidade Estadual Paulista, Campus de Botucatu, Botucatu-SP

2 - Graduanda em Medicina Veterinária da Faculdade de Medicina Veterinária da Universidade Estadual Paulista, Campus de Botucatu, Botucatu-SP

3 - Professora Assistente Doutora do Departamento de Clínica Veterinária da Faculdade de Medicina Veterinária da Universidade Estadual Paulista, Campus de Botucatu, Botucatu-SP

4 - Residente em Patologia Clínica da Faculdade de Medicina Veterinária da Universidade Estadual Paulista, Campus de Botucatu, Botucatu-SP

O linfoma é a neoplasia de tecido hematopoiético mais comum em càes. Sua classificaçào é baseada na localização anatômica e critérios histológicos. As formas multicêntrica, gastrointestinal e cutânea são as mais comuns, $\mathrm{e}$ as formas extranodais primárias, localizadas no globo ocular, sistema nervoso central (SNC), medula óssea, testículos ou cavidade nasal, sào menos comumente observadas. Este trabalho objetiva descrever um caso de linfoma 